\title{
An unusual diagnosis of a submandibular swelling
}

\author{
H Lancer ${ }^{1}$, E Ross ${ }^{2}$, D Olayaye ${ }^{2}, \mathrm{M} \mathrm{De}^{2}$ \\ 1 Walsall Hospitals NHS Trust \\ 2 University Hospitals Birmingham NHS Foundation Trust
}

\section{Case Report}

A 35 year old female presented to the ENT clinic with a year long history of an asymptomatic left submandibular lump. She had no notable risk factors and was otherwise fit and well.

On examination, a firm non-tender lump was palpated in left level I, and therefore an urgent ultrasound scan (USS) +/fine needle aspiration for cytology (FNAC), as well as computerised tomography (CT) with contrast was organised.

\section{Radiology}

USS revealed two small subcutaneous hypoechoic lesions, the largest being $5 \mathrm{~mm}$. These could have been reactive.

CT with contrast showed a normal appearance of bilateral submandibular glands, as well as no other abnormal findings.
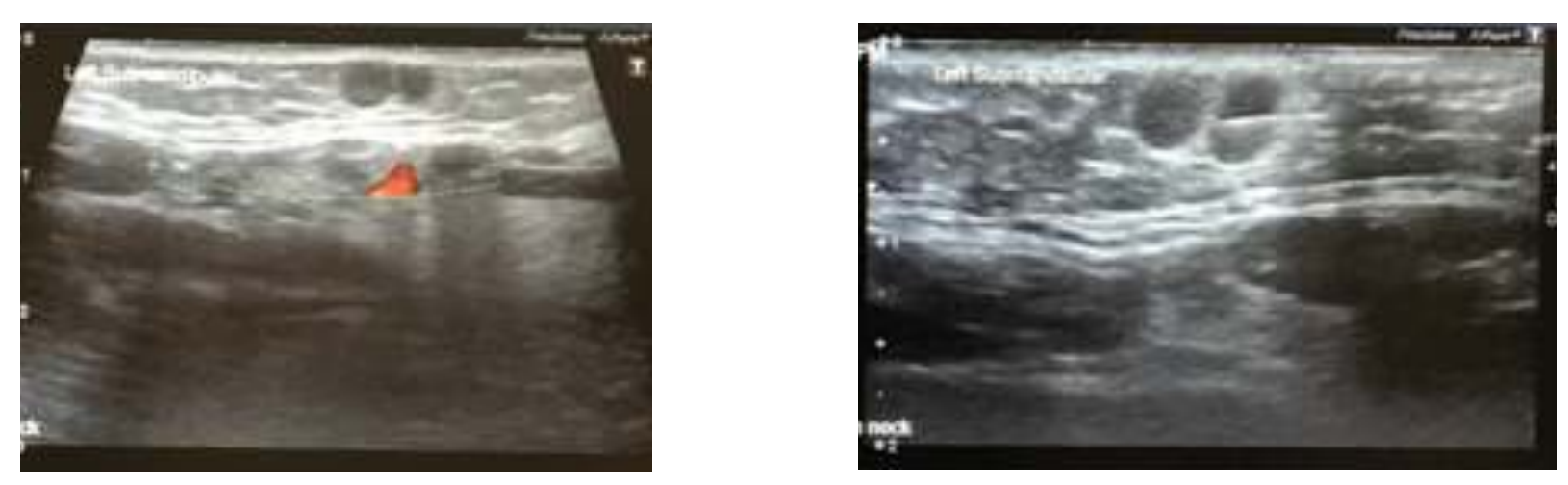

USS findings
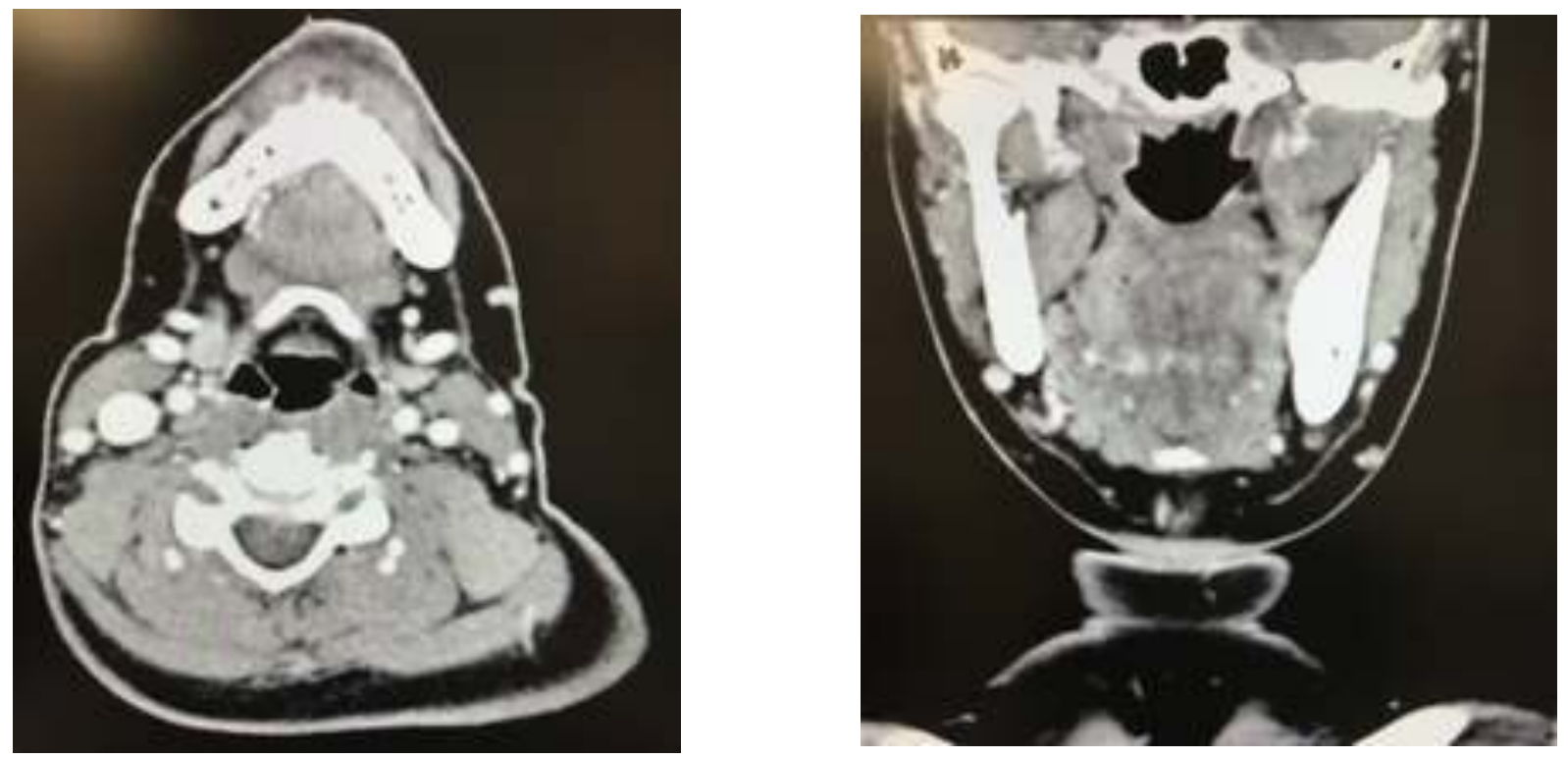

CT findings

\section{Histopathology (1)}

\section{FNAC}

'A few mixed inflammatory cells within a fibrinous background along with occasional tiny clusters of benignappearing epithelial cells. No atypia or malignant cells seen. The smears show multiple groups and sheets of epithelial cells arranged in acini which appear to be salivary gland acinic.

The features are suggestive of sampling of a salivary gland showing presence of a benign neoplasm.'

\section{Histopathology (2)}

With informed consent, the patient was listed for left level I clearance, and surgery was uneventful.

\section{Surgical specimen histology}

'A circumscribed encapsulated lesion composed of lobules containing small closely packed tubular structures with round laminae. These tubules contain eosinophilic material. A sprinkling of lymphocytes is noted. There is no obvious mitotic activity. No salivary gland tissue is identified here.

The features are not typical of a monomorphic adenoma, but in light of a subcutaneous lesion and absence of salivary gland tissue, the appearances are more in keeping with an eccrine spiradenoma.

\section{Discussion}

Eccrine spiradenomas are usually benign cutaneous adnexal lesions originating within the bulge of the hair follicle rather than the eccrine sweat gland. They demonstrate apocrine differentiation usually occurring between the 2nd to 4th decade.

They tend to arise on the ventral aspect of the body, most commonly on the head, neck and trunk.

The cause of a solitary spiradenoma has yet to be defined, but they are associated with Brooke-Spiegler syndrome (CYLD defect on chromosome 9). Malignant transformation is very rare. 1

Histopathology: The tumour is composed of sharply delineated basophilic nodules in the dermis, which occurs in sheets, cords or islands. The cell types present include small dark basaloid cells with hyperchromatic nuclei, and a larger cell with a pale nucleus which tends to be closer to the centre of the clusters. Lymphocytic infiltration is also not uncommon.

They can be mistaken histologically for synovial sarcomas, metastatic carcinoma, vascular tumours and adenoid cystic carcinoma, which have a single cell type, as opposed to eccrine spiradenomas which consist of three cell types (epithelial cells, myoepithelial cells, and lymphocytes).

\section{References}

1) https://emedicine.medscape.com/article/1062079-overview [Accessed 12/7/17]

2) Weedon's skin pathology fourth edition. 2016. Elsevier Limited. Book chapter James Patterson. 33, 903-965.E24 [Accessed online 12/7/17]

3) Comprehensive cytopathology fourth edition. 2015. Elsevier. Limited Book chapter Narasimhan Agaram and Oscar Lin. 18,363-402. E6 [Accessed online 12/7/17] 